2014-07-08

Homophobic bullying: evidence-based suggestions for intervention programmes

James Minton, S

http://hdl.handle.net/10026.1/15013

10.1108/jacpr-10-2013-0027

Journal of Aggression, Conflict and Peace Research

Emerald

All content in PEARL is protected by copyright law. Author manuscripts are made available in accordance with publisher policies. Please cite only the published version using the details provided on the item record or document. In the absence of an open licence (e.g. Creative Commons), permissions for further reuse of content should be sought from the publisher or author. 


\title{
Homophobic bullying: evidence-based suggestions for intervention programmes
}

\author{
Stephen James Minton
}

Dr Stephen James Minton is based at School of Education, Trinity College Dublin, Republic of Ireland.
This research was financially supported by awards made to the author by the Arts and Social Sciences Benefactions Fund Trinity College Dublin, Ireland.

\begin{abstract}
Purpose - The purpose of this paper is to investigate the influence of the basic factors of age and gender in homophobic bullying behaviour, in order that recommendations for the design of anti-bullying programmes specific to homophobic bullying could be made.

Design/methodology/approach - In total, 475 fifth year students (ca. 16-17 years old) and 561-second year students (ca. 13-14 years old) at six secondary schools in the Republic of Ireland completed an Englishlanguage translation of a questionnaire previously used in a Norwegian study of sexual orientation and bullying behaviour (Roland and Auestad, 2009).

Findings - No evidence of "age-related declines" were found in reports of either bullying or homophobic bullying. Males were significantly more likely than females to report involvement (as both perpetrators and targets) in both bullying and homophobic bullying.

Practical implications - It was concluded that senior secondary school students, as well as their younger counterparts, should be involved in anti-bullying interventions; that males should be especially focused upon; and that programmes specific to anti-homophobic bullying, potentially targeting pre-adolescent students, should be supported.

Originality/value - This paper suggests evidence-based priorities for intervention programmes specific to homophobic bullying, accounts of which have been, to date, absent in the research literature.

Keywords Gender, Homophobia, Age, Anti-bullying, Homophobic bullying, Intervention programmes

Paper type Research paper
\end{abstract}

\section{Bullying behaviour}

School bullying behaviour, which has been the subject of empirical research since the early 1970s (Olweus, 1999), is usually conceptualised as being a sub-type of the more general category of aggressive behaviour, and is differentiated from other forms of aggression on the basis of repetition (Olweus, 1993) and the existence of some form of power imbalance, in the perpetrator's favour, existing between the perpetrator and the target (Roland and Idsøe, 2001). Hence, a typical definition of bullying behaviour is "[...] long-standing violence, mental or physical, conducted by an individual or a group against an individual who is not able to defend himself or herself in that actual situation" (Roland, 1989 in Mellor, 1999). In the USA, Nansel et al.'s (2001) study of a representative sample of 15,686 sixth to tenth grade students in public and private schools showed that 29.9 per cent reported moderate or frequent involvement in bullying (13.0 per cent having bullied others, 10.6 per cent having been bullied, and 6.3 per cent having both bullied others and been bullied). Previously, general findings in Europe have been that males are more frequently involved in bully/victim problems (as perpetrators and targets) than are females (Smith et al., 1999, 2004), and that following a "peak" in involvement at around 13 years of age, there is a decline in involvement in bully/victim problems over the teenage years (Olweus, 1999; Smith and Sharp, 1994).

The past three decades have seen large-scale implementations of "whole-school" anti-bullying programmes at national and regional levels - initially, in the Nordic countries (Roland et al., 2010; 
Olweus and Roland, 1983), and subsequently, elsewhere (see Farrington and Ttofi, 2009; Smith et al., 1999, for reviews). However, evaluations of such programmes have yielded somewhat mixed results. Farrington and Ttofi's (2009) meta-analysis of the 44 anti-bullying programmes that provided data that permitted the calculation of an effect size for bullying or victimization (between 1983 and 2009) showed that, overall, school-based anti-bullying programmes succeeded in reducing bullying (on average, by between 20 and 23 per cent) and victimization (on average, by between 17 and 20 per cent). Merrell et al.'s (2008) meta-analysis of anti-bullying intervention research from 1980-2004, which included data from 15,000 students in Europe and North America, indicated that whole-school anti-bullying intervention programmes may produce modest positive outcomes, but that they are more likely to influence knowledge, attitudes, and self-perceptions rather than actual bullying behaviours.

Although it is not possible to state definitively whether this is a contributory factor to the relative modesty of the success rates of medium- to large-scale anti-bullying intervention programmes, it has been argued that prejudice has been insufficiently attended to in the design of such programmes (Minton, 2012; Mishna et al., 2009; Walton, 2006). Yet there is growing evidence of the existence of specific forms of bullying behaviour, such as homophobic bullying (Birkett et al., 2009; Mayock et al., 2009; Roland and Auestad, 2009), alterophobic (prejudice directed towards members of "alternative" sub-cultures' (e.g. punks, goths, emos, skaters, fans of heavy rock music)) bullying (Minton, 2012), and bullying that is related to the target's membership of an ethnic minority group (Hansen et al., 2008). For the purposes of the current paper, it is prudent to note that the finding that certain groups of people are more "at risk" of being bullied than others indicates that - at the very least - it is likely that prejudice exerts an influence on patterns of bullying behaviour (Minton, 2012).

\section{Homophobic bullying}

Eighteen years after Norwegian newspaper reports of three bullying-related suicides of school students in a single year ignited anti-bullying action in that country (Olweus, 1999), with Europewide and international repercussions (see Farrington and Ttofi, 2009; Smith et al., 1999, for reviews), US and subsequent international media reports were made of at least five specifically homophobic bullying-related teenage suicides in the USA in the single month of September 2010 (McKinley, 2010). Homophobia itself has been defined as "the fear of being labelled homosexual and the irrational fear, dislike or hatred of gay males and lesbians" (Blumenfeld and Raymond, 1998; in Norman et al., 2006, p. 36). Homophobic bullying has been characterised as taking place "where general bullying behaviour, such as verbal and physical abuse and intimidation, is accompanied by or consists of the use of terms such as gay, lesbian, queer or lezzie by perpetrators" (Warwick et al., 2001). This specific phenomenon, which is under investigation in the present study, is rooted in the rather restrictive (given larger conceptualisations of prejudice towards LGB persons) understanding of "homophobia". Herek (2000) prefers the term "sexual prejudice" in referring to negative attitudes towards an individual because of her or his sexual orientation because, unlike "homophobia", it "[...] conveys no assumptions about the motivations underlying negative attitudes, locates the study of attitudes concerning sexual orientation within the broader context of social psychological research on prejudice, and avoids value judgments about such attitudes" (p. 19). McDermott and Blair (2012) refer to the term "homonegativity", which refers to "[...] any prejudicial attitudes or any negative behavioural responses (including discriminatory behaviours) directed towards an individual because he or she is perceived to be homosexual" (p. 278). This construct has been sub-divided (Morrison and Morrison, 2002) into two related sub-constructs of "old-fashioned" (based on the understanding of homosexuality being morally/Biblically wrong, or psychopathological) and "modern" homonegativity (based on "[...] abstract concerns such as the belief that gay men and lesbian women are too demanding and seek special rights and privileges, or that sexual minorities have a tendency to flaunt their sexuality as a source of personal pride") (McDermott and Blair, 2012, p. 278). Even within homophobic bullying, it has been argued that two (often overlapping) sub-types may exist: a type that underpins the (often aggressive) heteronormativity of the school environment ("heteronormative bullying"), and the active persecution of known LGB persons ("sexual orientation-based bullying") (Minton et al., 2008).

\footnotetext{
VOL. 6 NO. 32014 | JOURNAL OF AGGRESSION, CONFLICT AND PEACE RESEARCH | PAGE 165
} 
In the investigation of homophobic bullying, Thurlow (2001) found that homophobic epithets accounted for 10 per cent of the pejoratives used by students in the English and Welsh schools in his sample. A study in lowa recorded that the average high school student heard anti-gay epithets around 25 times per day, yet teachers who heard these words failed to respond 97 per cent of the time (Flannery, 1999 in Chang and Kleiner, 2001). Canadian researchers Mishna et al. (2009) have also highlighted inaction regarding behavioural expressions of homophobia, asserting that "[...] the preponderance of bullying research does not address sexual orientation as a possible factor" (p. 1598). This same point has been argued consistently by their compatriot, Walton (2006), who asserts that, "[...] even though homophobia is a prominent feature of schoolyard bullying, it is also one of the most unchallenged forms of bullying" (p. 13). Although not numerous, some studies specific to homophobic bullying and its effects on non-heterosexual young people have been conducted. In Norway, when 3,046 (1,583 male, 1,463 female) tenth grade students (ca. 17-18 years of age in the Norwegian school system) completed a study-specific questionnaire on sexual orientation and bullying, it was found that 7.3 per cent of heterosexual, but 23.8 per cent of bisexual and 48.0 per cent of homosexual males, and 5.7 per cent of heterosexual, but 11.5 per cent of bisexual and 17.7 per cent of homosexual females, reported having been bullied in the last two to three months. Furthermore, depression and anxiety were higher amongst bisexual and homosexual students than they were amongst heterosexual students, and higher amongst bullied students than amongst non-bullied students (Roland and Auestad, 2009). However, the largest study of this type to date was conducted in the USA. Birkett et al.'s (2009) study of 7,376 seventh and eighth grade students (49.3 per cent male, 50.7 per cent female) from a large Midwestern county, indicated that LGB students and those questioning their orientations were more likely to report high levels of victimization, homophobic victimization, and other negative outcomes (drug use, truancy, depression, and suicidality).

Although anti-bullying intervention programmes have been implemented on a large and even national scale for three decades, to the best of this author's knowledge, accounts of large-scale, evidence-based, scientifically-evaluated school intervention programmes specific to homophobic bullying are notable only by their absence in the research literature. This is regrettable, given that Mishna et al.'s (2009) qualitative study revealed several dimensions specific to lesbian and gay youth (e.g. risks around "coming-out", sexual orientation-based prejudice in the media, and so-called "conversion" bullying). Furthermore, it has been argued that apparently non-targeted anti-bullying interventions in schools may be hampered by deficits of homophobia, heterosexism and heteronormativity (Walton, 2006). However, Birkett et al. (2009) concluded that schools do have the ability to lessen negative outcomes for LGB and sexually questioning students through creating positive climates and reducing homophobic bullying. The question that remains is as to how this may best be done.

The data that appears in the present study were drawn from participants in a single European country (the Republic of Ireland), and hence it is, of course, worth acknowledging that cultural specificity. Irish researchers Norman et al. (2006) have argued that homophobic bullying, rather than just being another form of bullying, is linked to negative societal attitudes towards people of non-heterosexual sexual orientation. Legally speaking, it is noteworthy that male homosexual sexual intercourse was decriminalised in Ireland as recently as 1993 (Bacik, 2004). Minton (2013) notes that this decriminalisation has not in itself, of course, brought about even legal equality. Irish law now prohibits discrimination, on the grounds of sexual orientation, in the areas of employment, vocational training, advertising, collective agreements, the provision of goods and services (since 2000) and the incitement to hatred based on sexual orientation (since 1989). (Bacik, 2004; Minton, 2013). However, whilst the legal arrangements around civil partnership provides for home protection, maintenance, pension entitlements, it does not provide for same-sex couples to be legally married, nor to adopt jointly, or have joint guardianship over children they raise together (Minton, 2013). In their demonstration of specific sociocultural differences in prejudice towards gay men and lesbian women in Canada, Ireland, the USA, and the UK, McDermott and Blair (2012) note that "[...] 91.9\% of the Irish population are members of the Catholic Church, an institution widely acknowledged to hold conservative views on homosexuality, and that has wielded a significant amount of power and influence over Irish political and social development until recent times" (p. 279). A total of 1,003 respondents from

PAGE 166 | JOURNAL OF AGGRESSION, CONFLICT AND PEACE RESEARCH | VOL. 6 NO. 32014 
those four nations completed online measures of homonegativity, the highest levels of which were found amongst participants in the USA, and the lowest (which the authors describe as "unexpected") in the Republic of Ireland. It was noted that lower levels of homonegativity in the USA and the Republic of Ireland were correlated with higher self-reported levels of education (McDermott and Blair, 2012).

So, education, and as noted above (Birkett et al., 2009), schools in particular, can make a difference. However, as far as schools in Ireland go, the previous research that exists indicates homophobic bullying would seem to be a serious issue. In a study of 725 SPHE (Social, Personal and Health Education) teachers' views and perceptions of homophobic bullying (Norman et al., 2006), it was found that 79 per cent of the teachers in the sample were aware of verbal homophobic bullying, and 16 per cent were aware of physical bullying related to homophobia. Furthermore, O'Higgins-Norman argued that in the relationships and sexuality education (RSE) component of SPHE, there was an "[...] absence of any teaching about sexual orientation [which] contributes to homophobic bullying among students in Irish schools" (p. 69). A study of 1,100 LGBT (lesbian, gay, bisexual and transgender) people in the Republic of Ireland showed that 58 per cent reported the existence of homophobic bullying in their schools, and 5 per cent had actually left school early because of homophobic bullying (Mayock et al., 2009).

The purpose of this study, then, was to investigate incidence rates of bullying behaviour and homophobic bullying behaviour amongst secondary school students in Ireland. Unlike afore-mentioned studies in Norway (Roland and Idsøe, 2001) and the USA (Birkett et al., 2009), prior to the gathering of the data reported on in this study, no empirical study of self-reported bullying behaviour and sexual orientation amongst young people themselves had been conducted in the Republic of Ireland. To a large extent, then, although previous research on teachers (Norman et al., 2006) and recollections of adult LGB people (Mayock et al., 2009) indicated a concerning level of prevalence of homophobic bullying, this study was necessarily exploratory. It was also sought to determine to what extent the very basic demographic factors of age and gender exert upon such behaviours, in order that evidence-based priorities for intervention programmes might be suggested.

\section{Method}

\section{Sample}

This study utilised a cross-sectional design, involving the analysis of data sets obtained from two age cohorts. The first was obtained in May, 2010, from the questionnaire responses of 475 fifth year students (ca. 16-17 years old), 274 of whom were male (57.7 per cent), and 201 of whom were female (42.3 per cent). This comprised all of those students who were present at school on the day the questionnaire was administered at six secondary schools distributed over the geographical area of the Republic of Ireland. The schools involved included a balance of singlegender and co-educational student enrolment, rural/urban location, and types of secondary schools, in line with national characteristics. The second data set was obtained in May, 2011, from the questionnaire responses of 561 second year students (ca. 13-14 years old) 317 of whom were male ( 56.5 per cent), and 201 of whom were female ( 43.5 per cent). Again, this comprised all of those students who were present at school on the day the questionnaire was administered at the same six schools.

\section{Materials}

The student participants in both the fifth year and the second year samples completed an English-language translation (Minton, 2011) of the written questionnaire constructed specifically for, and previously used, in a Norwegian study of sexual orientation and bullying behaviour (Roland and Auestad, 2009). After first obtaining the prior consent of the schools' principals and relevant management authorities, the questionnaire was administered by the students' teachers, according to written standardised instructions, on site in the schools in ordinary class time. On the questionnaire, participants were instructed, "Please try to answer the following questions as carefully and as honestly as you can. There are no right or wrong answers - choose the answer(s) which match(es) your opinion", and "Don't put your name on this form. No-one will 
know how you have answered these questions". On the questionnaire itself, bullying behaviour was defined for the participants as follows: "We say it is bullying when a person or people together are repeatedly unfriendly and unpleasant to someone who cannot easily defend himself or herself. This can involve the bullied person being hit, kicked or otherwise physically hurt. It is also bullying when a person is teased or excluded by others".

\section{Measures}

Student participants' self-reported experiences of bullying and two categories of homophobic bullying (name-calling and rumour-spreading) were assessed in the questionnaire items - whether, and how frequently, participants had done such things to others, or if it had happened to them (indicating either "never", "seldom", "two or three times per month", "about every week", or "about every day" as appropriate).

\section{Procedure}

In May 2010 (fifth year sample) and May 2011 (second year sample), following communication with and having obtained informed consent from the school principals/relevant school management authorities, sufficient copies of the questionnaire, and standardized instructions for its administration to students, were sent to the six participating schools. Although no absolute time limit was to be set, it was noted that it should ordinarily take no longer than ten to 15 minutes for a student to complete the questionnaire. Students were to be seated separately. Questionnaires were to be filled in entirely anonymously and confidentially; schools and individuals were assured that they could and would not be identified by their participation in the survey, which would be treated as a matter of absolute privacy. Afterwards, the class teacher administrators collected up the questionnaires, and the schools posted them back to the author. Following the processing of the results, school principals were supplied with a copy of their own school's anonymous, group-based results. Given the exploratory nature of the study, the novelty of the data-gathering instrument, and the variables under consideration (self-reported involvement in bullying behaviour, self-reported involvement in homophobic bullying behaviour, age and gender), the data that emerged were nominal in nature. Parametric statistics thus being precluded, the data treatment was simple, involving a strategic set of $\chi^{2}$ analyses of the nominal data obtained from the two age cohort sets.

\section{Results}

As males and females are generally found to have different incidences and patterns of involvement in bullying behaviour (Smith et al., 1999), results from males and females in the fifth and second year samples are presented separately; and, in making age-related comparisons, "total" figures are avoided. However, as the male-female gender proportions were almost identical in the fifth and second year samples ( 57.7 vs 42.3 per cent, and 56.5 vs 43.5 per cent, respectively), it has been possible to make comparisons of the "fifth year male versus second year male" type.

\section{Bullying behaviour}

In terms of the factor of gender in bullying behaviour, within both the fifth and second year samples, males were statistically significantly more likely than females to report having been bullied (36.5 vs 27.9 per cent, $\chi^{2}=3.92, \mathrm{df}=1, p<0.05$; and, 41.0 vs 31.1 per cent, $\chi^{2}=5.77$, $\mathrm{df}=1, p<0.05$, respectively). So too were males, again in both the fifth and second year samples, statistically significantly more likely than females, to have bullied others (40.1 vs 14.9 per cent, $\chi^{2}=35.83, \mathrm{df}=1, p<0.001$ and 36.9 vs 14.8 per cent, $\chi^{2}=33.81, \mathrm{df}=1, p<0.001$, respectively). Whereas it was statistically significantly more likely for females to report having been bullied (27.9 per cent vs 14.9 per cent, $\chi^{2}=10.16$, $\mathrm{df}=1, p<0.01$ ) than having bullied others (31.1 vs 14.8 per cent, $\chi^{2}=18.30, \mathrm{df}=1, p<0.001$ ), this was not true of males. In terms of the factor of age, there were no statistically significant differences between the fifth and second year samples (in total, for males only, or for females only) in reports of having been bullied or having bullied others (see Table I).

PAGE 168 | JOURNAL OF AGGRESSION, CONFLICT AND PEACE RESEARCH | VOL. 6 NO. 32014 


\begin{tabular}{|c|c|c|c|c|c|c|}
\hline Response category & Male $(n=274)$ & Female $(n=201)$ & Total $(n=475)$ & Male $(n=317)$ & Female $(n=244)$ & Total $(n=561)$ \\
\hline Never & 63.5 & 72.1 & 67.2 & 59.0 & 68.9 & 63.3 \\
\hline Seldom & 24.5 & 24.4 & 24.4 & 27.4 & 24.2 & 26.0 \\
\hline Two or three times per month & 6.2 & 2.0 & 4.4 & 7.3 & 4.5 & 6.1 \\
\hline About every week & 4.7 & 0.5 & 2.9 & 3.5 & 1.6 & 2.7 \\
\hline About every day & 1.1 & 1.0 & 1.1 & 2.8 & 0.8 & 2.0 \\
\hline \multicolumn{7}{|c|}{ Percentages of students who reported having bullied others } \\
\hline & Male $(n=274)$ & Female $(n=202)$ & Total $(n=476)$ & Male $(n=317)$ & Female $(n=243)$ & Total $(n=560)$ \\
\hline Never & 59.9 & 85.1 & 70.6 & 63.1 & 85.2 & 72.7 \\
\hline Seldom & 29.9 & 13.4 & 22.9 & 32.8 & 13.6 & 24.5 \\
\hline Two or three times per month & 5.5 & 1.0 & 3.6 & 4.1 & 0.4 & 2.5 \\
\hline About every week & 2.6 & 0.5 & 1.7 & 0 & 0.4 & 0.2 \\
\hline About every day & 2.2 & 0 & 1.3 & 0 & 0.4 & 0.2 \\
\hline
\end{tabular}

\section{Homophobic bullying behaviour}

In terms of the factor of gender in homophobic bullying behaviour, within both the fifth year and second year samples, males were statistically significantly more likely to report having been homophobically bullied through name-calling than were females (18.2 vs 9.0 per cent, $\chi^{2}=8.16$, $\mathrm{df}=1, p<0.01)$. Males were also statistically significantly more likely to report having homophobically bullied others through name-calling (39.8 vs 13.4 per cent, $\chi^{2}=39.75, \mathrm{df}=1$, $p<0.001)$. This was not the case in reports of having been homophobically bullied through rumour-spreading. Furthermore, whilst second year males were statistically significantly more likely to report having been homophobically bullied through rumour-spreading than were females (8.8 vs 2.9 per cent, respectively, $\chi^{2}=8.38$, $\mathrm{df}=1, p<0.01$ ), there were no such significant differences within the fifth year sample. In terms of the influence of age, second year males were statistically significantly more likely to report having been homophobically bullied through name-calling than were fifth year males (25.2 vs 18.2 per cent, respectively, $\chi^{2}=4.18$, $\mathrm{df}=1, p<0.05)$. However, there were no such significant differences in the total and female only samples. Nor were there significant differences between the fifth and second year samples (in total, for males only, or for females only) in reports of having been homophobically bullied, or having homophobically bullied others, through rumour-spreading (see Tables II and III).

Fifth year males, and males and females in the second year sample, were statistically significantly more to report having homophobically bullied others through name-calling than to have been targeted themselves in this way (39.8 vs 18.2 per cent, $\chi^{2}=30.84$, df $=1, p<0.001$; 45.4 vs 25.2 per cent, $\chi^{2}=28.27, \mathrm{df}=1, p<0.001$; and, 18.4 vs 6.6 per cent, $\chi^{2}=15.76$,

Table II Students' self-reported involvement in homophobic bullying behaviour through name-calling

$$
\text { Fifth year }
$$

\section{Second year}

Percentages of students who reported having been homophobically bullied by being called "gay" or "lesbian"

\begin{tabular}{|c|c|c|c|c|c|c|}
\hline Response category & Male $(n=274)$ & Female $(n=201)$ & Total $(n=475)$ & Male $(n=317)$ & Female $(n=244)$ & Total $(n=561)$ \\
\hline Never & 81.8 & 91.0 & 85.7 & 74.8 & 93.4 & 82.9 \\
\hline Seldom & 9.9 & 5.0 & 7.8 & 16.1 & 4.9 & 11.2 \\
\hline Two or three times per month & 3.3 & 2.5 & 2.9 & 4.4 & 1.2 & 3.0 \\
\hline About every week & 2.9 & 1.0 & 2.1 & 1.9 & 0 & 1.1 \\
\hline About every day & 2.2 & 0.5 & 1.5 & 1.3 & 0.4 & 1.8 \\
\hline \multicolumn{7}{|c|}{ Percentages of students who reported having homophobically bullied others by calling them "gay" or "lesbian" } \\
\hline & Male $(n=274)$ & Female $(n=202)$ & Total $(n=476)$ & Male $(n=317)$ & Female $(n=244)$ & Total $(n=561)$ \\
\hline Never & 60.2 & 86.6 & 71.4 & 54.6 & 81.6 & 66.3 \\
\hline Seldom & 24.8 & 8.4 & 17.9 & 30.0 & 16.0 & 23.9 \\
\hline Two or three times per month & 4.7 & 1.0 & 3.2 & 10.4 & 1.2 & 6.4 \\
\hline About every week & 4.7 & 1.5 & 3.4 & 3.2 & 0 & 1.8 \\
\hline About every day & 5.5 & 2.5 & 4.2 & 1.9 & 1.2 & 1.6 \\
\hline
\end{tabular}


Table III Students' self-reported involvement in homophobic bullying behaviour through rumour-spreading

$$
\text { Fifth year Second year }
$$

Percentages of students who reported having been homophobically bullied by having rumours spread that they were "gay" or "lesbian" Response category Male $(n=274) \quad$ Female $(n=200) \quad$ Total $(n=474) \quad$ Male $(n=317) \quad$ Female $(n=244) \quad$ Total $(n=561)$

\begin{tabular}{llllll} 
Never & 93.5 & 93.5 & 93.4 & 91.2 & 97.1 \\
\hline
\end{tabular}

$\begin{array}{lll}\text { Seldom } & 4.4 & 5.0 \\ \text { Two or three times per month } & 1.1 & 1.0\end{array}$

$\begin{array}{lll}\text { About every week } & 0.7 & 0.5\end{array}$

About every day

0.4

$4.6 \quad 5.0$

1.6

0.2

1.6
1.6

2.5

3.9

1.1

0.9

Percentages of students who reported having homophobically bullied others by spreading rumours that they were "gay" or "lesbian"

\begin{tabular}{|c|c|c|c|c|c|c|}
\hline & Male $(n=274)$ & Female $(n=202)$ & Total $(n=476)$ & Male $(n=317)$ & Female $(n=244)$ & Total $(n=561)$ \\
\hline Never & 87.6 & 91.6 & 89.3 & 91.2 & 97.1 & 93.8 \\
\hline Seldom & 6.2 & 7.4 & 6.7 & 6.9 & 2.9 & 5.2 \\
\hline Two or three times per month & 2.6 & 0.5 & 1.7 & 1.3 & 0 & 0.7 \\
\hline About every week & 1.1 & 0 & 0.6 & 0.6 & 0 & 0.4 \\
\hline About every day & 2.6 & 0.5 & 1.7 & 0 & 0 & 0 \\
\hline
\end{tabular}

$\mathrm{df}=1, p<0.001$, respectively), but this was not true of fifth year females. Finally, males in the fifth year sample were statistically significantly more likely to report having homophobically bullied others through rumour-spreading than to report having been targeted themselves in this way (12.4 vs 6.5 per cent, respectively, $\chi^{2}=5.43, \mathrm{df}=1, p<0.05$ ), but this was not true of fifth year females, nor of second year males and females (see Tables II and III).

\section{Discussion of results}

To reiterate, the purpose of this study was to investigate incidence rates of bullying behaviour and homophobic bullying behaviour amongst secondary school students in Ireland. It was also sought to determine to what extent the very basic demographic factors of age and gender exert upon such behaviours, in order that evidence-based priorities for intervention programmes might be suggested.

The overall findings regarding gender confirmed those of previous studies others regarding a more frequent level of male involvement in bullying (Nansel et al., 2001; Smith et al., 1999, 2004). Age did not exert as great an effect; this seemingly contradicts some earlier studies, which have suggested a general decline in involvement in bully/victim problems with increasing age (Olweus, 1999; Nansel et al., 2001; Smith et al., 1999). Most generally speaking, the incidences of homophobic bullying observed in this study support Walton's (2006) assertion that homophobia is a prominent feature of school bullying. Again, age did not exert as great an effect on the observed incidence rates of homophobic bullying as did gender. Males were more likely to report involvement (as targets and as perpetrators) in both of the forms of homophobic bullying examined in this study, and again, there was no evidence of an "age-related decline" in such involvement. Such findings, combined with those of Mishna et al. (2009), which showed that several dimensions of bullying may be specific to lesbian and gay youth, and Walton's (2006) arguments that general anti-bullying interventions in schools may be hampered by deficits of homophobia, heterosexism, and heteronormativity, evidence that a case can be made to design and implement interventions specific to homophobic bullying.

In the case of bullying behaviour, most categories of participants were statistically significantly less likely to report being a perpetrator of such behaviour than they were to report having been targeted in this way, again confirming earlier and general findings (see Smith et al., 1999). However, in this study, we have seen that the reverse was true in most categories of homophobic bullying. How are such differences to be explained? In attempting to do so, one might recall to the description that was offered of homophobia as being "[...] the fear of being labelled homosexual and the irrational fear, dislike or hatred of gay males and lesbians" (Blumenfeld and Raymond, 1998 in Norman et al., 2006, p. 36; italics mine). Identifying oneself as a target of homophobic bullying is to acknowledge that, in the eyes of the perpetrator(s), one could have a non-heterosexual orientation; and if homophobia has been internalised (or an expression of such been socially learned), then this is an unlikely course of action.

PAGE 170 | JOURNAL OF AGGRESSION, CONFLICT AND PEACE RESEARCH $\mid$ VOL. 6 NO. 32014 
Although a feasible extension of this interpretation, it is not valid, on the basis of these data sets, to interpret the finding that no "age-related decline" in homophobic bullying was observed in this study as being indicative that homophobic attitudes remain unchecked in the secondary school years. As we have seen, no "age-related decline" in bullying was apparent in this study, either. Hence, it is equally possible that both absences of "age-related declines" are explicable by general attitudes towards bullying remaining unchecked. What is certain from the second year sample data, however, is that both bullying and homophobic bullying are already in evidence by the early adolescent years, and that the attitudes that underpin these behaviours - homophobia and pro-aggression - are, therefore, likely to have formed prior to this age. Hence, if preadolescent (elementary school years) intervention has been emphasised in intervening against bullying behaviour (Farrington and Ttofi, 2009; Smith et al., 1999, 2004), then on the basis of these results it is surely logically consistent to apply the same approach in intervening against homophobia and homophobic bullying.

\section{Limitations}

As we have seen, the instrument that was chosen to measure bullying and homophobic bullying in this study was an English-language translation (Minton, 2011) of that designed and utilised by Roland and Auestad (2009). The basis of this choice was the initial attempt to ensure comparability between data sets obtained in Norway and Ireland, which was indeed accomplished (Minton, 2011). Nevertheless, in terms of comparison with other data sets, the study is limited as the psychometric properties and validity of the chosen instrument are less apparent than those of others that have been developed, either prior to this research in the USA (Poteat and Espelage, 2005) or subsequently in Europe (Prati, 2012). However, the purpose of this study was humble enough; that is to say, to make suggestions regarding priorities for intervention programmes based on an understanding of the extent to which the very basic demographic factors of age and gender exert upon self-reported incidence rates of bullying behaviour and homophobic bullying behaviour amongst a sample of high school-aged students.

It is questionable, given the culture-specific factors that pertain to data regarding attitudes towards sexual orientation gathered in a single European nation (see McDermott and Blair, 2012), how "universal" these findings might be. Future research in this area in Ireland could utilise larger and even nationally representative samples; it is also recommended that a more psychometrically robust instrument should be selected. In this way, a more definitive expression of the validity of the measures might be ensured, thus permitting the possibility of international comparability. As culture-specific factors seem to apply, these international comparisons are surely warranted.

\section{Implications for practice}

- Senior secondary school students as well as their younger counterparts should be actively involved in anti-bullying interventions.

- Males should be especially focused upon in anti-bullying and anti-homophobic bullying interventions.

- The observed prevalence of self-reports of homophobic bullying, allied to the finding that students were more likely to identify as perpetrators rather than as targets of homophobic bullying, demonstrates that there are cases to be made for attending to the influence of prejudice in the development of hopefully more effective anti-bullying programmes; and developing programmes specific to anti-homophobic bullying.

- It may be useful for anti-homophobic bullying programmes to target pre-adolescent school students.

\section{References}

Bacik, I. (2004), Kicking and Screaming: Dragging Ireland into the 21st Century, O'Brien Press, Dublin.

Birkett, M., Espelage, D.L. and Koenig, B. (2009), "LGB and questioning students in schools: the moderating effects of homophobic bullying and school climate on negative outcomes", Journal of Youth and Adolescence, Vol. 38 No. 7, pp. 989-1000. 
Chang, C.W. and Kleiner, B.H. (2001), "New developments concerning discrimination and harassment of gay students", International Journal of Sociology and Social Policy, Vol. 21 No. 8, pp. 108-15.

Farrington, D.P. and Ttofi, M.M. (2009), School-Based Programs to Reduce Bullying and Victimization, Campbell Systematic Reviews, Oslo.

Hansen, K.L., Melhus, M., Høgmo, A. and Lund, E. (2008), "Ethnic discrimination and bullying in the Sami and non-Sami populations in Norway: the SAMINOR study", International Journal of Circumpolar Health, Vol. 67 No. 1, pp. 97-113.

Herek, G. (2000), "The psychology of sexual prejudice”, Current Directions in Psychological Science, Vol. 9 No. 1, pp. 19-22.

McDermott, D.T. and Blair, K.L. (2012), “'What's it like on your side of the pond?': a cross-cultural comparison of modern and old-fashioned homonegativity between North American and European samples", Psychology \& Sexuality, Vol. 3 No. 3, pp. 277-96.

McKinley, J. (2010), "Suicides put light on pressures of gay teenagers", New York Times, 3 October, available at: www.nytimes.com

Mayock, P., Bryan, A., Carr, N. and Kitching, K. (2009), Supporting LGBT Lives: A Study of the Mental Health and Well-Being of Lesbian, Gay, Bisexual and Transgender People, GLEN and BeLonG To, Dublin.

Mellor, A. (1999), "Scotland", in Smith, P.K., Morita, Y., Junger-Tas, J., Olweus, D., Catalano, R.F. and Slee, P. (Eds), The Nature of School Bullying: A Cross-National Perspective, Routledge, London, pp. 91-111.

Merrell, K.W., Gueldner, B.A., Ross, S.W. and Isava, D.M. (2008), "How effective are school bullying intervention programs? A meta-analysis of intervention research", School Psychology Quarterly, Vol. 23 No. 1, pp. 26-42.

Minton, S.J. (2011), "Experiences of and perspectives on homophobic bullying amongst a sample of upper secondary school students in Ireland", Presented at the 15th European Conference on Developmental Psychology, Bergen, 23-27 August.

Minton, S.J. (2012), "Alterophobic bullying and pro-conformist aggression in a survey of upper secondary school students in Ireland", Journal of Aggression, Conflict and Peace Research, Vol. 4 No. 2, pp. 86-95.

Minton, S.J. (2013), "Homophobic bullying in schools in Ireland”, in O'Moore, A.M. and Stevens, P. (Eds), Bullying in Irish Education, Cork University Press, Cork, pp. 65-79.

Minton, S.J., Dahl, T., O'Moore, A.M. and Tuck, D. (2008), "An exploratory survey of the experiences of homophobic bullying among lesbian, gay, bisexual and transgender young people in Ireland", Irish Educational Studies, Vol. 27 No. 2, pp. 177-91.

Mishna, F., Newman, P.A., Daley, A. and Solomon, S. (2009), "Bullying of lesbian and gay youth: a qualitative investigation", British Journal of Social Work, Vol. 39 No. 8, pp. 1598-614.

Morrison, M.A. and Morrison, T.G. (2002), "Development and validation of a scale measuring modern prejudice toward gay men and lesbian women”, Journal of Homosexuality, Vol. 43 No. 2, pp. 15-37.

Nansel, T.R., Overpeck, M., Pilla, R.S., Ruan, W.J., Simons-Morton, B. and Scheidt, P. (2001), "Bullying behaviours among US Youth: prevalence and association with psychosocial adjustment", Journal of the American Medical Association, Vol. 285 No. 16, pp. 2094-100

Norman, J., Galvin, M. and McNamara, G. (2006), Straight Talk: Researching Gay and Lesbian Issues in the School Curriculum, Department of Education and Science Gender Equality Unit, Dublin.

Olweus, D. (1993), Bullying: What We Know and What We Can Do, Blackwell, Oxford.

Olweus, D. (1999), "Sweden, Norway”, in Smith, P.K., Morita, Y., Junger-Tas, J., Olweus, D., Catalano, R.F. and Slee, P. (Eds), The Nature of School Bullying: A Cross-National Perspective, Routledge, London, pp. 7-48.

Olweus, D. and Roland, E. (1983), Mobbing (Bullying), Kirke- og Undervisnings departmentet, Oslo.

Poteat, V.P. and Espelage, D.L. (2005), "Exploring the relation between bullying and homophobic verbal content: the Homophobic Content Agent Target (HCAT) Scale", Violence and Victims, Vol. 20 No. 5, pp. 513-28, available at: http://dx.doi.org/10.1891/0886-6708.2005.20.5.513

Prati, G. (2012), "Development and psychometric properties of the homophobic bullying scale”, Educational and Psychological Measurement, Vol. 72 No. 4, pp. 649-64.

PAGE 172 | JOURNAL OF AGGRESSION, CONFLICT AND PEACE RESEARCH | VOL. 6 NO. 32014 
Roland, E. and Auestad, G. (2009), Seksuell orienteering og mobbing (Sexual Orientation and Bullying) Universitetet i Stavanger, Senter for atferdsforskning, Stavanger.

Roland, E. and Idsøe, T. (2001), "Aggression and bullying”, Aggressive Behavior, Vol. 27 No. 6, pp. 446-61.

Roland, E., Bru, E., Midthassel, U.V. and Vaaland, G.S. (2010), "The Zero programme against bullying: effects of the programme in the context of the Norwegian manifesto against bullying", Social Psychology of Education, Vol. 13 No. 1, pp. 41-55.

Smith, P.K. and Sharp, S. (Eds) (1994), School Bullying: Insights and Perspectives, Routledge, London.

Smith, P.K., Pepler, D. and Rigby, K. (2004), Bullying in Schools: How Effective Can Interventions Be? Cambridge University Press, Cambridge.

Smith, P.K., Morita, Y., Junger-Tas, J., Olweus, D., Catalano, R.F. and Slee, P. (Eds) (1999), The Nature of School Bullying: A Cross National Perspective, Routledge, London.

Thurlow, C. (2001), "Naming the 'outsider within': homophobic pejoratives and the verbal abuse of lesbian, gay and bisexual high-school pupils", Journal of Adolescence, Vol. 24 No. 1, pp. 25-38, available at: http:// dx.doi.org/10.1006/jado.2000.0371

Walton, G. (2006), "H-cubed: a primer on bullying and sexuality diversity for educators", Professional Development Perspectives, Vol. 6 No. 2, pp. 13-20.

Warwick, I., Aggleton, P. and Douglas, N. (2001), "Playing it safe: addressing the emotional and physical health of lesbian and gay pupils in the UK", Journal of Adolescence, Vol. 24 No. 1, pp. 129-40.

\section{Corresponding author}

Dr Stephen James Minton can be contacted at: mintonst@tcd.ie

To purchase reprints of this article please e-mail: reprints@emeraldinsight.com

Or visit our web site for further details: www.emeraldinsight.com/reprints

VOL. 6 NO. 32014 | JOURNAL OF AGGRESSION, CONFLICT AND PEACE RESEARCH | PAGE 173 